Nachrichten der Deutschen Gesellschaft für Nuklearmedizin

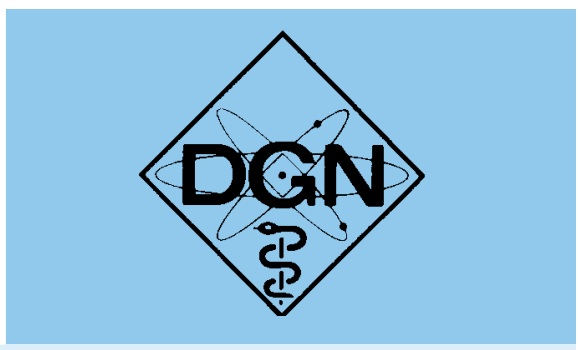

\title{
DGN-Summer School 2020
}

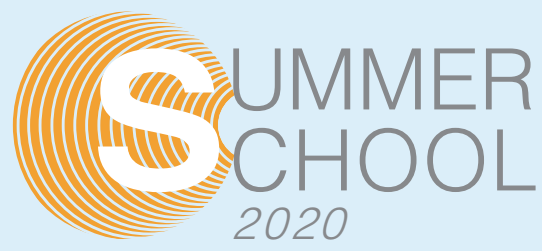

Wir freuen uns, auch in diesem Jahr vom 27. bis 29. August 2020 die DGN-Summer School an der Charité in Berlin zum Thema „Translational Research in Molecular Imaging and Radionuclide Therapy“ durchzuführen. Die wissenschaftliche Leitung liegt erneut bei Prof. Dr. Winfried Brenner, Berlin (D), Prof. Dr. Martin Gotthardt, Nijmegen $(\mathrm{NL})$, und Prof. Dr. Felix M. Mottaghy, Aachen und Maastricht (NL).

Die DGN-Summer School ist ein internationales, englischsprachiges Forum, das sich an Studierende, Doktoranden sowie junge Nachwuchswissenschaftler aus den Bereichen (Nuklear-) Medizin, Biologie, Physik und Chemie in den ersten Jahren ihrer Weiterbildung richtet. Ziel ist es, den wissenschaftlichen Nachwuchs für die Nuklearmedizin und die molekulare Bildgebung zu begeistern, in Forschungsaktivitäten zu integrieren und langfristig in die translationalen Bereiche des Fachgebiets einzubinden.

Maximal 30 Teilnehmer werden im Rahmen der 3-tägigen DGN-Summer School in Vorträgen, Falldemonstrationen sowie Handson-Veranstaltungen verschiedene Themen wissenschaftlich fundiert und praxisnah aktiv kennenlernen und gemeinsam mit den Dozenten intensiv diskutieren können. Als Referenten werden hochkarätige, natio-

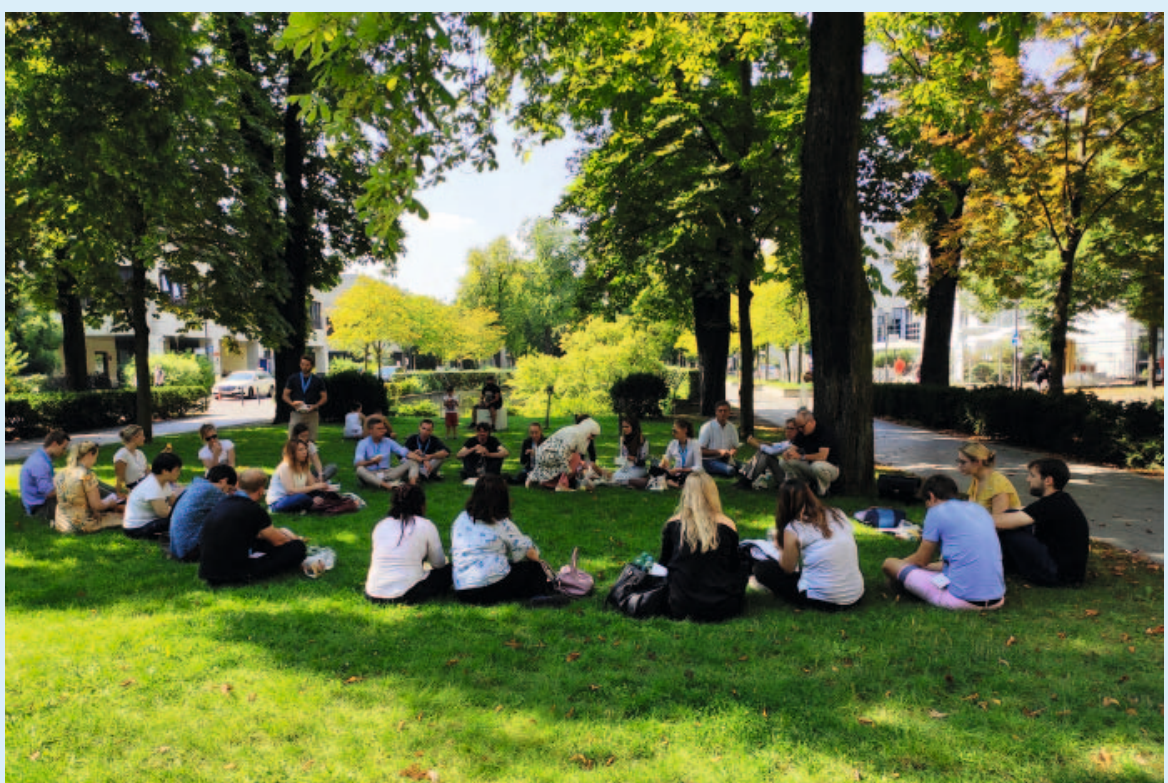

Lunchpause bei der DGN-Summer School 2019.

nale wie auch internationale Experten des jeweiligen Themenbereichs eingeladen. Gemeinsame Abendveranstaltungen runden das Programm ab und ermöglichen auch außerhalb der Veranstaltungen einen regen Austausch zwischen Teilnehmern und Tutoren.

\section{Teilnahme}

Die Auswahl der Teilnehmer für die DGNSummer School erfolgt auf Grundlage der einzureichenden Bewerbungsunterlagen:

- Lebenslauf,

- Motivationsschreiben und

- Unterstützungsschreiben des Leiters Ihrer Einrichtung, an der Sie beschäftigt sind.
Bitte senden Sie Ihre Bewerbung - in Deutsch oder Englisch - per Mail bis zum 31. Mai 2020 an die DGN-Geschäftsstelle. Später eintreffende Bewerbungen können im Auswahlverfahren leider nicht mehr berücksichtigt werden. Erfolgreiche Bewerber erhalten ein Stipendium, das Übernachtungs- und Verpflegungskosten sowie die Kurskosten abdeckt.

Allen interessierten Nachwuchswissenschaftlern und an der Unterstützung der DGNSummer School interessierten Unternehmen steht die DGN-Geschäftsstelle gerne per E-Mail unter office@nuklearmedizin.de oder telefonisch unter 0551/48 857-401 für weitere Auskünfte zur Verfügung. 